$\underline{\text { Research Article }}$

\title{
A VALIDATED STABILITY INDICATING UV-SPECTROPHOTOMETRIC SIMULTANEOUS ESTIMATION OF ROSUVASTATIN CALCIUM AND FENOFIBRATE IN BULK AND PHARMACEUTICAL FORMULATION
}

\author{
APEKSHA FUNDE ${ }^{a^{*}}$, JAYSHREE KOKAT ${ }^{\mathrm{b}}$ \\ aDepartment of Pharmaceutics, bDepartment of Pharmaceutical Chemisrty, Abasaheb Kakade College of B. Pharmacy, Bodhegaon 414503, \\ Ahmednagar, Maharashtra \\ Email: fundeapeksha5@gmail.com
}

Received: 26 Sep 2020 Revised and Accepted: 25 Nov 2020

\begin{abstract}
Objective: The present work deals with the development and validation of the absorbance ratio method for the estimation of rosuvastatin calcium and fenofibrate in bulk and pharmaceutical formulation. Studied forced degradation characteristics of bulk and pharmaceutical formulation as per stability guidelines.
\end{abstract}

Methods: The bulk and pharmaceutical formulation studied by the absorbance ratio method. It is the ratio of absorbances at two selected wavelengths. One wavelength is the isoabsorptive point and another wavelength is $\lambda$ max of one of the components. From the overlay spectra of the two drugs, ROS and FEN showed the isoabsorptive point at $249.5 \mathrm{~nm}$. The second wavelength used was $287 \mathrm{~nm}$, which was the $\lambda$ max of FEN.

Results: The drugs obeyed Beer's law and showed a good correlation. The correlation coefficient for the ROS was 0.999 and for FEN 0.999. The RSD for intraday precision was 0.57 for ROS and 0.057 for FEN. The interday precision was 0.05 for ROS and 0.03 for FEN, respectively. The detection limit and quantification limit were found to be 0.048 and $0.14 \mu \mathrm{g} / \mathrm{ml}$ for ROS and 0.069 and $0.21 \mu \mathrm{g} / \mathrm{ml}$ for FEN, respectively. More degradation was found in acid hydrolysis and photostability degradation.

Conclusion: A simple, precise, accurate, validated, stability-indicating method for simultaneous estimation of rosuvastatin calcium and fenofibrate in bulk and pharmaceutical formulation has been developed.

Keywords: Correlation coefficient, Detection limit, Precision, Pharmaceutical, Quantification limit, Spectrophotometric, Ultraviolet, $\lambda$ max, \% RSD

(C) 2021 The Authors. Published by Innovare Academic Sciences Pvt Ltd. This is an open access article under the CC BY license (http://creativecommons.org/licenses/by/4.0/) DOI: http://dx.doi.org/10.22159/ijcr.2021v5i1.144. Journal homepage: https://ijcr.info/index.php/journal

\section{INTRODUCTION}

Chemically rosuvastatin calcium is (3R, 5S, 6E)-7-[4-(4-fluorophenyl)-2-(N-methylmethanesulfonamido)-6-(propane-2-yl)pyrimidin-5-yl]-3,5dihydroxyhept-6-enoic acid. It belongs to the statin group of drugs. Rosuvastatin reduces the amount of cholesterol made by the liver reducing LDL, triglyceride, and raising HDL in the blood. It decreases the risk of heart disease and helps to prevent heart attack and stroke [1].

Chemically fenofibrate is (Propan-2-yl 2-[4-(4-chlorobenzoyl) phenoxy]-2-methylpropanoate). Fenofibrate is a fabric acid derivative. It is used to improve cholesterol levels in mixed dyslipidemia, severe hypertriglyceridemia, and Primary hypercholesterolemia. It helps lower triglycerides and helps increase levels of HDL cholesterol [2, 3].

In the treatment of mixed dyslipidemia, there is a need to reduce the LDL-C and triglyceride levels. The combined therapy of rosuvastatin calcium and fenofibrate is the most effective option to increase HDL-C [4].

A literature survey showed Anandakumar K et al. [5] reported UV-spectrophotometry and RP-HPLC method for simultaneous estimation of this combination in bulk and tablet dosage form. Sevda RR et al. [6] reported UV-spectrophotometric simultaneous equation method for the estimation of rosuvastatin calcium and fenofibrate in bulk drug and dosage form. Potawale RS et al. [7] revealed the HPTLC method for the simultaneous determination of this combination bulk and pharmaceutical formulation. Sharma S et al. [8] reported UV-spectrophotometry and RP-HPLC method. Borole TC et al. [9] reported the HPLC method for simultaneous estimation. Patel H et al. [10] reported simultaneous quantification by using HPLCUV of rosuvastatin and fenofibric acid in rat plasma and its application to a pharmacokinetic study. Trivedi RK et al. [11] determined rosuvastatin and fenofibric acid in human plasma by LC-MS/MS. Kumar SA et al. [12] developed a validated sensitive RP-HPLC method for simultaneous estimation of this combination in tablet dosage form by using a PDA detector in gradient mode. Vyas S et al. [13] developed a validated derivative spectroscopic method in a combined dosage form.

The literature review revealed that rosuvastatin-fenofibrate is not studied by the absorbance ratio method (isoabsorptive point method) and their stability is also not determined. So the present work was directed towards try to develop UV-spectrophotometric simultaneous estimation of rosuvastatin calcium and fenofibrate by absorbance ratio method in bulk as well as the tablet dosage form. The method was validated as per ICH guidelines and a forced degradation study performed to check their stability.

\section{MATERIALS AND METHODS}

Chemicals and reagents

Working standards of fenofibrate and rosuvastatin calcium were procured from yarrowchem products Pvt. Ltd. Thane. Methanol AR grade, NaOH (AR grade), $\mathrm{HCl}$ ( $\mathrm{AR}$ grade), $30 \% \mathrm{H}_{2} \mathrm{O}_{2}$ (AR grade) were used in the present study. Razat F10 tablet was procured from the market and used for the present study. 


\section{Apparatus}

A UV spectrophotometer Shimadzu corporation KYOTO, Japan (1700 pharmaspec A-11024302261 LP) was used for the experiment. Afcoset electronic balance (FX 300), Ultrasonicator labline 1-5L-50, Microwave oven york scientific industries, Delhi, Photostability chamber makes newtronic (Model IC DAC version 1.2) was used.

\section{Preparation of standard stock solution}

$20 \mathrm{mg}$ of standard ROS were weighed and transferred to $100 \mathrm{ml}$ of volumetric flasks and dissolved in methanol. The flasks were shaken and volumes were made up to mark with methanol to give a solution containing $200 \mu \mathrm{g} / \mathrm{ml}$ of rosuvastatin calcium.160 mg of standard FEN were weighed and transferred to $100 \mathrm{ml}$ of volumetric flasks and dissolved in methanol. The flasks were shaken and volumes were made up to mark with methanol to give a solution containing $1600 \mu \mathrm{g} / \mathrm{ml}$ of fenofibrate.

\section{Selection of detection wavelength}

An aliquot portion of the stock solution of ROS and FEN was diluted to $10 \mathrm{ml}$ of methanol in $10 \mathrm{ml}$ of the volumetric flask to obtain a standard stock solution of $16 \mu \mathrm{g} / \mathrm{ml}$. These solutions were scanned over the range of $200-400 \mathrm{~nm}$ and the spectra were obtained. Rosuvastatin calcium showed considerable absorbance at $243 \mathrm{~nm}$ and fenofibrate showed considerable absorbance at $287 \mathrm{~nm}$.

\section{Preparation of calibration curve}

Prepared the concentrations of 4, 8, 12,16, 20, and $24 \mu \mathrm{g} / \mathrm{ml}$ respectively by taking aliquot portions of ROS and FEN from stock and diluted individually to $10 \mathrm{ml}$ with methanol in $10 \mathrm{ml}$ of volumetric flasks. The absorbance of diluted solutions was measured at $243 \mathrm{~nm}$ and $287 \mathrm{~nm}$ respectively, against methanol as blank. The graph is plotted as Absorbance vs. concentration.

\section{Absorbance ratio method}

To calculate conc. of drugs in the mixture absorbance ratio method was used. The absorbance ratio method uses the ratio of absorbance at two selected wavelengths, one wavelength is the isoabsorptive point and the other being the $\lambda$ max of other components. From the overlay spectra of the two drugs, ROS and FEN showed the isoabsorptive point at $249.5 \mathrm{~nm}$. The second wavelength used was $287 \mathrm{~nm}$, which was the $\lambda$ max of FEN.

The concentration of two drugs in a mixture can be calculated using the following equations.

$$
\begin{aligned}
& C x=\frac{Q M-Q Y}{Q X-Q Y} \times \frac{A 1}{a X 1} \\
& C y=\frac{Q M-Q X}{Q Y-Q X} \times \frac{A 1}{a Y 1}
\end{aligned}
$$

Where $\mathrm{A} 1$ and $\mathrm{A} 2$ are absorbances of the mixture at $249.5 \mathrm{~nm}$ and $287 \mathrm{~nm}$.

aX1 and aY1 are absorptivities of ROS and FEN, respectively [14].

\section{Preparation of mixed standard solution}

Accurately weighed $10 \mathrm{mg}$ of rosuvastatin calcium and $160 \mathrm{mg}$ fenofibrate transferred into $100 \mathrm{ml}$ dry and clean volumetric flask and $50 \mathrm{ml}$ of methanol was added. This mixed standard solution was sonicated for $10 \mathrm{~min}$ and then volume made up to mark with methanol. The prepared solution was subjected to UV analysis. Take appropriate aliquot in a $10 \mathrm{ml}$ volumetric flask and diluted up to mark with methanol to get the resulting solution containing the $16 \mu \mathrm{g} / \mathrm{ml} \mathrm{FEN} \mathrm{and} 1 \mu \mathrm{g} / \mathrm{ml}$ ROS. The absorbance of the resulting solutions was measured at $249.5 \mathrm{~nm}$ and $287 \mathrm{~nm}$. The concentration of both drugs in the mixture was calculated by using the equation of the absorbance ratio method. The Amount of drug estimated in the sample in $(\mathrm{mg})$ and percent estimation was calculated.

\section{Analysis of marketed formulation}

\section{Razat F10 (Rosuvastatin calcium $10 \mathrm{mg}$, Fenofibrate $160 \mathrm{mg}$ )}

Accurately weighed $10 \mathrm{mg}$ of ROS and $160 \mathrm{mg}$ of FEN of tablet powder was transferred into $100 \mathrm{ml}$ of a volumetric flask, $20 \mathrm{ml}$ of methanol was added, sonicated, and diluted up to $100 \mathrm{ml}$. The resultant solution was filtered through Whatman filter paper and transferred to a $100 \mathrm{ml}$ volumetric flask and diluted with methanol to get a solution containing $100 \mu \mathrm{g} / \mathrm{ml} \mathrm{ROS}$ and $1600 \mu \mathrm{g} / \mathrm{ml}$ of FEN. $0.1 \mathrm{ml}$ of solution was transferred to a $10 \mathrm{ml}$ volumetric flask and diluted up to mark with methanol to get a solution containing the $1 \mu \mathrm{g} / \mathrm{ml} \mathrm{ROS}$ and $16 \mu \mathrm{g} / \mathrm{ml} \mathrm{FEN}$. The absorbances of resulting solutions were measured at $249.5 \mathrm{~nm}$ and $287 \mathrm{~nm}$. The concentration of ROS and FEN present in standard mixture and amount of drug estimated in $\mathrm{mg} / \mathrm{tab}$ and percent label claim was calculated by the equation of absorbance ratio method.

\section{Validation of the proposed method}

\section{Linearity}

The linearity of the established method is achieved by running a series of a standard mixture of ROS and FEN. Standard calibration data was calculated.

\section{Precision}

The reproducibility of the proposed method was determined by performing the assay for the same day (intraday assay precision) and on three different days (interday precision). Precision studies were performed by preparing nine determinations of the specified range for the procedure $(3 \mathrm{x}$ 3 replicates for each concentration). Low \% RSD shows that the method has good precision [12].

\section{Accuracy}

The standard addition method is used to determine accuracy. Known amounts of standard solutions of ROS and FEN were added at $80 \%, 100 \%$, and $120 \%$ level to quantified sample solutions of ROS and FEN $(1 \mu \mathrm{g} / \mathrm{ml}$ for ROS and $16 \mu \mathrm{g} / \mathrm{ml}$ for FEN). The amount of drug recovered (mg) and percent recovery was calculated [13].

\section{Robustness}

The robustness of this proposed method was checked by changing the analyst and other conditions remained the same as UV spectrophotometer, solvent, dilutions [13]. 


\section{Limit of detection and limit of quantification}

The LOD and LOQ were determined based on the standard calibration curve. The residual standard deviation of the y-intercept of regression lines may be used to calculate LOD and LOQ using the following equations [12].

$$
\begin{aligned}
& \mathrm{LOD}=3.3 * \mathrm{D} / \mathrm{S} \\
& \mathrm{LOQ}=10^{*} \mathrm{D} / \mathrm{S}
\end{aligned}
$$

\section{Stability studies of standard mixture and formulation}

\section{Acid hydrolysis}

$0.1 \mathrm{ml}$ working standard solution and formulation of ROS and FEN was mixed with $1 \mathrm{ml}$ of $0.1 \mathrm{~N}$ HCL and volume makeup to 10 ml with methanol (i. e $1: 16 \mu \mathrm{g} / \mathrm{ml}$ ). The solution was kept overnight. The absorbance of the resulting solution was measured at $249.5 \mathrm{~nm}$ and $287 \mathrm{~nm}$ [15].

\section{Alkali hydrolysis}

$0.1 \mathrm{ml}$ working standard solution of ROS and FEN was mixed with $1 \mathrm{ml}$ of $0.1 \mathrm{~N} \mathrm{NaOH}$ and volume makeup to $10 \mathrm{ml}$ with methanol in $10 \mathrm{ml}$ of the volumetric flask to give (i. e1:16 $\mu \mathrm{g} / \mathrm{ml}$ ). The solution was kept for $6 \mathrm{~h}$. The absorbance of the resulting solution was measured at $243 \mathrm{~nm}$ and 287 $\mathrm{nm}[16]$.

\section{Oxidative hydrolytic degradation}

$0.1 \mathrm{ml}$ working standard solution and formulation of ROS and FEN was exposed with $1 \mathrm{ml}$ of $3 \% \mathrm{H}_{2} \mathrm{O}_{2}$ and volume makeup to $10 \mathrm{ml}$ with methanol in $10 \mathrm{ml}$ of the volumetric flask to give (i. e $1: 16 \mu \mathrm{g} / \mathrm{ml}$ ). The solution was kept for $6 \mathrm{~h}$. The absorbance of the resulting solution was measured at $249.5 \mathrm{~nm}$ and $287 \mathrm{~nm}$ [17].

\section{Degradation under dry heat}

Dry heat studies were performed by keeping the drug sample in an oven at $80{ }^{\circ} \mathrm{C}$ for $24 \mathrm{~h} .10 \mathrm{mg}$ of ROS and $160 \mathrm{mg}$ of FEN was weighed and dissolved in $100 \mathrm{ml}$ methanol. $0.1 \mathrm{ml}$ working standard solution of was mixed with $9.9 \mathrm{ml}$ methanol in $10 \mathrm{ml}$ of the volumetric flask (i. e 1:16 $\mu \mathrm{g} / \mathrm{ml})$. The solution was kept for $6 \mathrm{~h}$. The absorbance of the resulting solution was measured at $249.5 \mathrm{~nm}$ and $287 \mathrm{~nm}$ [17].

\section{Photodegradation study}

The photostability study of the drug was determined by exposing the drug under UV light, which provides illumination of NLT 200 watt $\mathrm{hr} / \mathrm{m}^{2}$ followed by cool white sunlight. After each exposure, accurately $1: 16 \mu \mathrm{g} / \mathrm{ml}$ photo exposed solution made for absorbance. The absorbance of the resulting solution was measured at $249.5 \mathrm{~nm}$ and $287 \mathrm{~nm}$ [18].

\section{RESULTS}

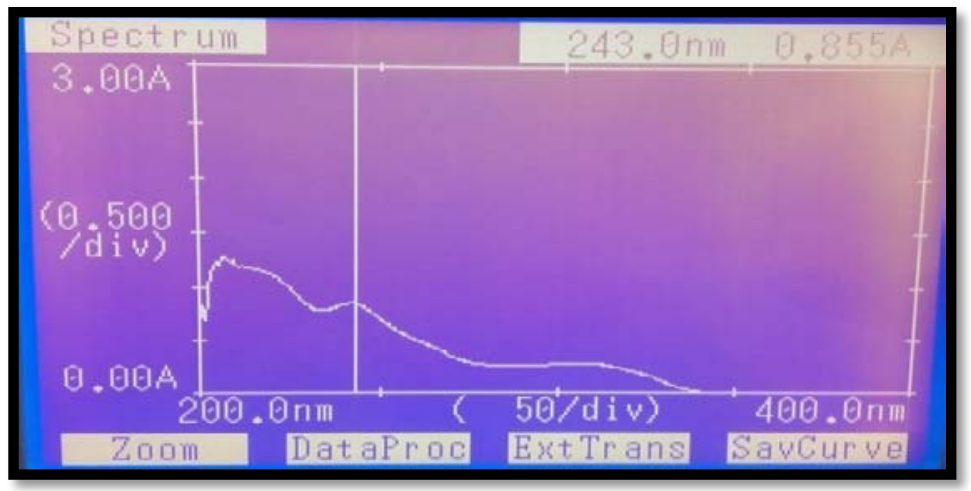

Fig. 1: UV absorption spectrum of ROS

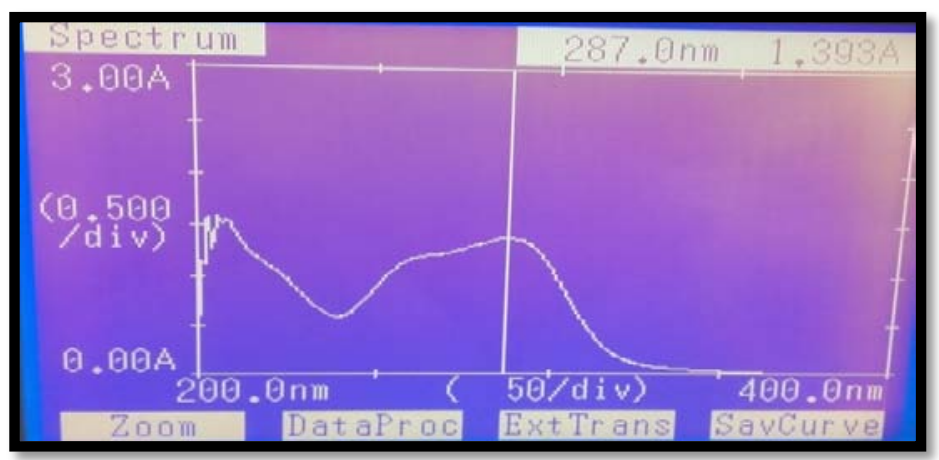

Fig. 2: UV absorption spectrum of FEN 


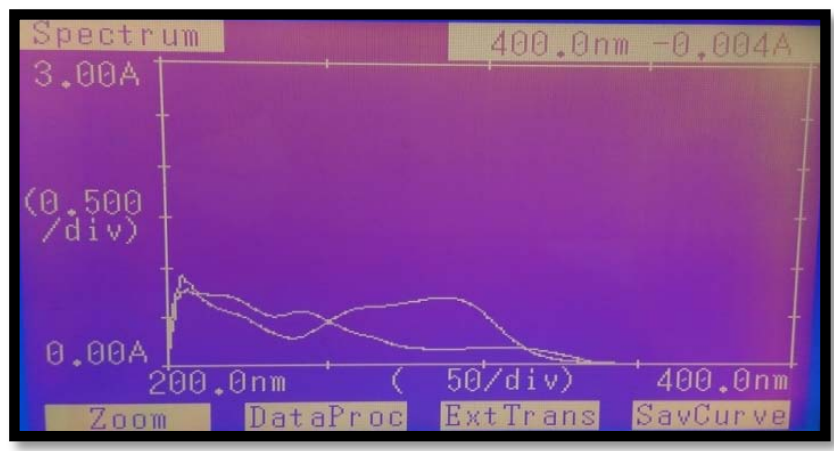

Fig. 3: Overlay spectra of ROS and FEN

The UV scanning spectrum of rosuvastatin calcium and fenofibrate showed the $\lambda$ max at $243 \mathrm{~nm}$ as shown in fig. 1 and $287 \mathrm{~nm}$ as shown in fig. 2 , respectively. Overlay spectra of both drugs showed is absorptive point at $249.5 \mathrm{~nm}$ as shown in fig. 3 .

Table 1: Standard calibration data for rosuvastatin calcium and fenofibrate

\begin{tabular}{lll}
\hline & Rosuvastatin calcium & Fenofibrate \\
\hline Concentration range & $4-24$ & $4-24$ \\
Correlation coefficient & 0.999 & 0.999 \\
Intercept & $0.042 \mathrm{x}$ & $0.053 \mathrm{x}$ \\
Slope & 0.0477 & 0.054 \\
\hline
\end{tabular}

Table 1 shows the linearity of this method was studied in the range $4-24 \mu \mathrm{g} / \mathrm{ml}$ for ROS and FEN, respectively. Calibration curved showed a linear relationship between absorbance and concentrations. The linearity equation for ROS was found to be $y=0.042 x+0.001$ with a correlation coefficient 0.999 as shown in table 1 and fig. 4 . The linearity equation for FEN was found to be $y=0.052 x+0.008$ with a correlation coefficient 0.999 as shown in table 1 and fig. 5.

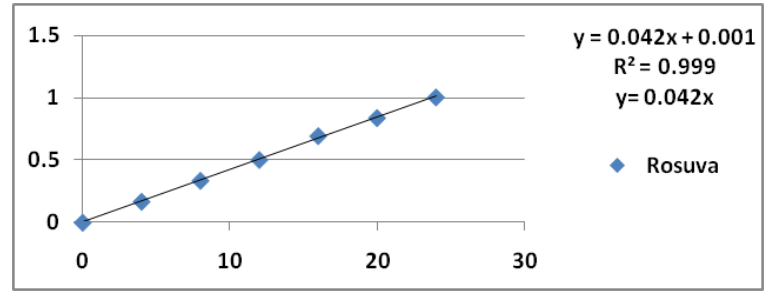

Fig. 4: Calibration curve of rosuvastatin calcium

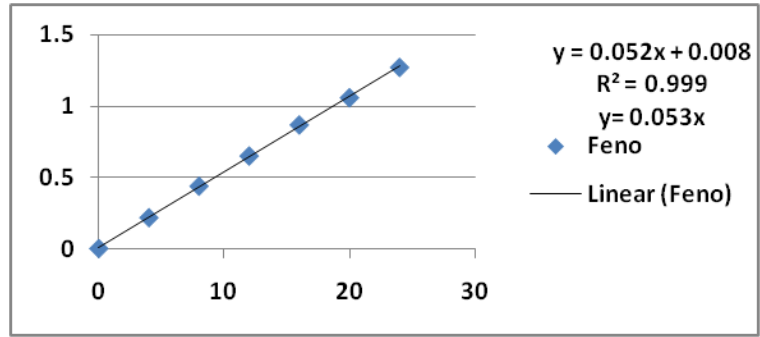

Fig. 5: Calibration curve of fenofibrate

Table 2: Results analysis of standard laboratory mixture $(n=6)$

\begin{tabular}{|c|c|c|c|c|c|c|c|c|}
\hline \multirow[t]{2}{*}{ S. No. } & \multicolumn{2}{|c|}{ Amt. of a drug taken $(\mu \mathrm{g} / \mathrm{ml})$} & \multicolumn{2}{|c|}{ Absorbance (nm) } & \multicolumn{2}{|c|}{ Amt. of drug estimated (mg) } & \multicolumn{2}{|l|}{$\%$ Estimation } \\
\hline & ROS & FEN & 249.5 & 287 & ROS & FEN & ROS & FEN \\
\hline 1 & 1 & 16 & 0.580 & 0.920 & 10 & 160 & 100 & 100 \\
\hline 2 & 1 & 16 & 0.580 & 0.920 & 10 & 160 & 100 & 100 \\
\hline 3 & 1 & 16 & 0.582 & 0.923 & 10.02 & 161 & 100.2 & 100.61 \\
\hline 4 & 1 & 16 & 0.580 & 0.920 & 10 & 160 & 100 & 100 \\
\hline 5 & 1 & 16 & 0.581 & 0.921 & 10.02 & 161 & 100.2 & 100.61 \\
\hline \multirow[t]{3}{*}{6} & 1 & 16 & 0.580 & 0.920 & 10 & 160 & 100 & 100 \\
\hline & & & & & & mean $\pm S D$ & $100.06 \pm 0.103$ & $100.20 \pm 0.315$ \\
\hline & & & & & & \% RSD & 0.102 & 0.314 \\
\hline
\end{tabular}

Mean Average of six determinations, SD: Standard Deviation, \% RSD: Percentage relative standard deviation, The amount of drug estimated and percentage estimation are shown in table 2 . 
Table 3: Results analysis of marketed formulation $(n=6)$

\begin{tabular}{|c|c|c|c|c|c|c|c|}
\hline \multirow{2}{*}{$\begin{array}{l}\text { S. } \\
\text { No. }\end{array}$} & \multirow{2}{*}{$\begin{array}{l}\text { Weight of tablet } \\
\text { powder (gm) }\end{array}$} & \multicolumn{2}{|c|}{ Absorbance } & \multicolumn{2}{|c|}{ Amt. of drug estimated (mg) } & \multicolumn{2}{|l|}{ \% Estimation } \\
\hline & & $249.5 \mathrm{~nm}$ & $287 \mathrm{~nm}$ & ROS & FEN & ROS & FEN \\
\hline 1 & 0.420 & 0.596 & 0.937 & 10 & 160 & 100 & 100 \\
\hline 2 & 0.422 & 0.598 & 0.939 & 10.02 & 160.02 & 100.2 & 100.2 \\
\hline 3 & 0.421 & 0.597 & 0.938 & 10.01 & 160.01 & 100.1 & 100.1 \\
\hline 4 & 0.420 & 0.596 & 0.937 & 10 & 160 & 100 & 100 \\
\hline 5 & 0.422 & 0.598 & 0.939 & 10.02 & 160.02 & 100.2 & 100.2 \\
\hline \multirow[t]{3}{*}{6} & 0.420 & 0.596 & 0.937 & 10 & 160 & 100 & 100 \\
\hline & & & & & mean $\pm S D$ & $100.08 \pm 0.0983$ & $100.08 \pm 0.0983$ \\
\hline & & & & & $\%$ RSD & 0.098 & 0.098 \\
\hline
\end{tabular}

Mean: Average of six determinations, SD: Standard Deviation, \% RSD: Percentage relative standard deviation, the amount of drug estimated and percentage estimation are shown in table 3.

Validation of the analytical method

Table 4: Results of accuracy study (n=3)

\begin{tabular}{lllll}
\hline Amount added & Amount found \pm SD & & \% Recovery \pm \% RSD \\
\cline { 2 - 5 } & ROS & FEN & ROS & FEN \\
\hline 80 & $0.41 \pm 1.44$ & $0.081 \pm 0.721$ & $100.83 \pm 1.39$ & $100.41 \pm 0.71$ \\
100 & $0.51 \pm 1.15$ & $0.11 \pm 1.15$ & $100.66 \pm 1.14$ & $100.66 \pm 1.14$ \\
120 & $0.61 \pm 0.958$ & $0.121 \pm 0.479$ & $100.55 \pm 0.95$ & $100.55 \pm 0.47$ \\
\hline
\end{tabular}

n: no. of determinations taken at each recovery level, SD: Standard Deviation, \% RSD: Percentage relative standard deviation, The \% recovery was calculated and it was found to be within the prescribed limit as shown in table 4.

Table 5: Results of precision data of ROS and FEN (n=3)

\begin{tabular}{lllll}
\hline & Interday precision & & Intraday precision & \\
\hline & ROS & FEN & ROS & FEN \\
\hline mean \pm SD & $0.566 \pm 0.00404$ & $0.906 \pm 0.004$ & $0.569 \pm 0.00057$ & $0.909 \pm 0.000577$ \\
$\%$ RSD & 0.57 & 0.05 & 0.57 & 0.03 \\
\hline
\end{tabular}

Mean: Average of 3 determinations SD: Standard Deviation, \% RSD: Percentage relative standard deviation, the above table represents the results of interday and intraday precision data of ROS and FEN calculated by taking a mean of 3 determinations. The \% RSD of the absorbance is less than $2 \%$ so the method was found to be precise.

Table 6: Results of robustness study $(n=3)$

\begin{tabular}{llll}
\hline ROS & FEN & \%RSD \\
\hline mean \pm SD & \%RSD & mean \pm SD & 0.34 \\
\\
$0.336 \pm 0.001$ & 0.29 & $0.436 \pm 0.0015$ & 0.23 \\
$0.504 \pm 0.0015$ & 0.30 & $0.648 \pm 0.0015$ & 0.11 \\
$0.695 \pm 0.0015$ & 0.21 & $0.867 \pm 0.001$ & \\
\hline
\end{tabular}

SD: Standard Deviation, \% RSD: Percentage relative standard deviation, the robustness of the method was calculated by changing the analyst and it was found to be within a limit as shown in table 6 .

Table 7: Result of LOD and LOQ

\begin{tabular}{lll}
\hline Parameter & ROS & FEN \\
\hline LOD $(\mu \mathrm{g} / \mathrm{ml})$ & 0.0480 & 0.069 \\
$\mathrm{LOQ}(\mu \mathrm{g} / \mathrm{ml})$ & 0.145 & 0.210 \\
\hline
\end{tabular}

LOD: Limit of detection LOQ: Limit of quantification, the detection limit and quantification limit were found to be 0.048 and $0.14 \mu \mathrm{g} / \mathrm{ml}$ for rosuvastatin and 0.069 and $0.210 \mu \mathrm{g} / \mathrm{ml}$ for fenofibrate, respectively, as shown in table 7 .

Table 8: Forced degradation study

\begin{tabular}{lllllll}
\hline S. No. & Stress condition control & Time & $\begin{array}{l}\text { Standard Mix. \% } \\
\text { obtained }\end{array}$ & $\begin{array}{l}\text { Standard mix. \% } \\
\text { degraded }\end{array}$ & $\begin{array}{l}\text { Formulation \% } \\
\text { obtained }\end{array}$ & $\begin{array}{l}\text { Formulation \% } \\
\text { degraded }\end{array}$ \\
\hline 1 & Acid hydrolysis(0.1 N HCl) & $6 \mathrm{~h}$ & 84.2 & 15.8 & 87.21 & 12.7 \\
2 & Alkali hydrolysis (0.1 N & $6 \mathrm{~h}$ & 95.77 & 4.3 & 99.68 & 0.32 \\
& NaOH) & $6 \mathrm{~h}$ & 99.32 & 0.68 & 96.85 & 3.14 \\
3 & Oxidation (3\% H202) & $6 \mathrm{~h}$ & 94.9 & 5.10 & 61.86 & 1.14 \\
4 & Thermal (80 $\left.{ }^{\circ} \mathrm{Cfor} 6 \mathrm{~h}\right)$ & $5 \mathrm{~h}$ & 61.86 & 38.14 & 48.44 & \\
5 & $\begin{array}{l}\text { Photo Stability } \\
\text { Sun Light 6 h }\end{array}$ & & & & \\
\hline
\end{tabular}

The above table represents the results of the forced degradation study of standard mixture and formulation. \% degradation and \% obtained was calculated for each stress condition. Photostability degradation and acid hydrolysis showed prominent degradation. 


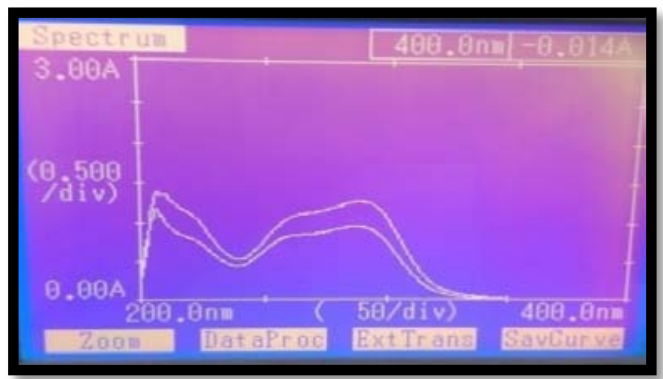

Std. mixture

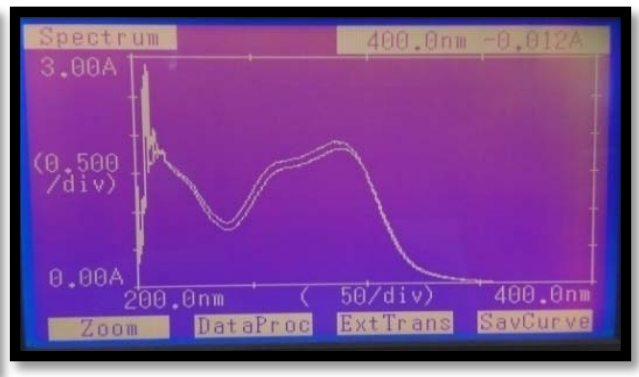

Formulation

Fig. 6: Acid degradation of standard mixture and formulation

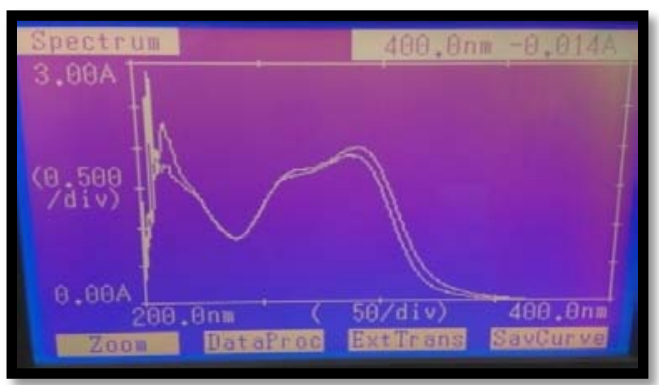

Std. mixture

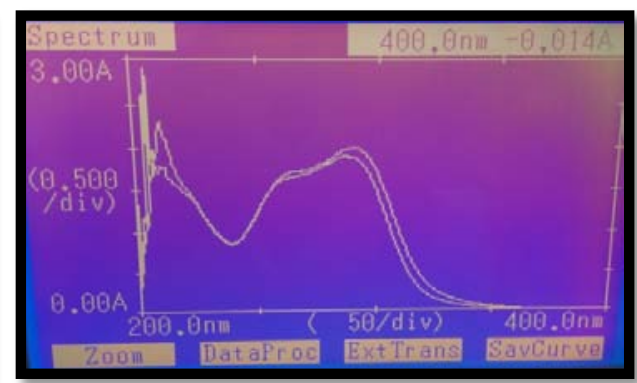

Formulation

Fig. 7: Base degradation of standard mixture and formulation

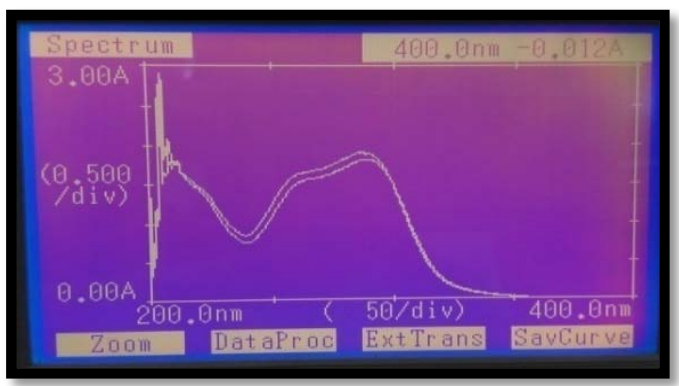

Std. mixture

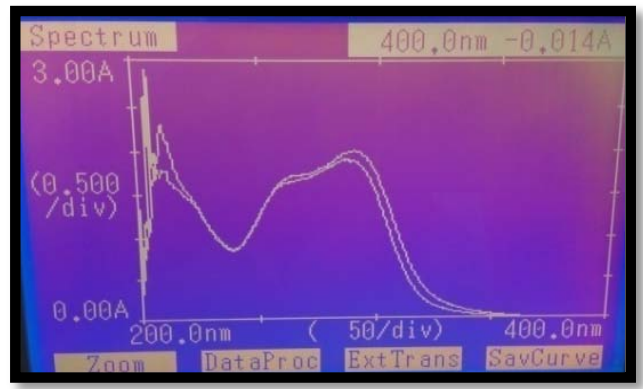

Formulation

Fig. 8: $\mathrm{H}_{2} \mathrm{O}_{2}$ degradation of standard mixture and formulation

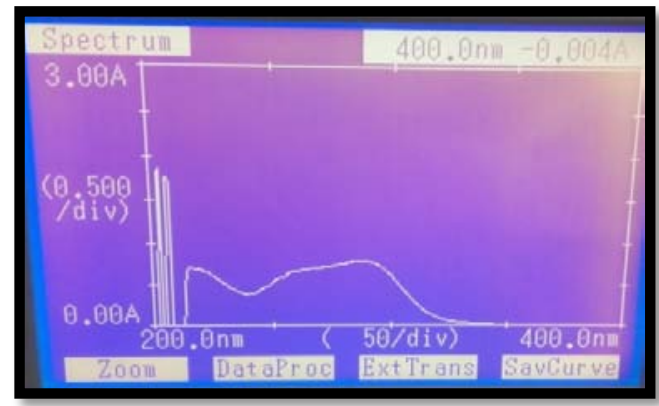

Std. mixture

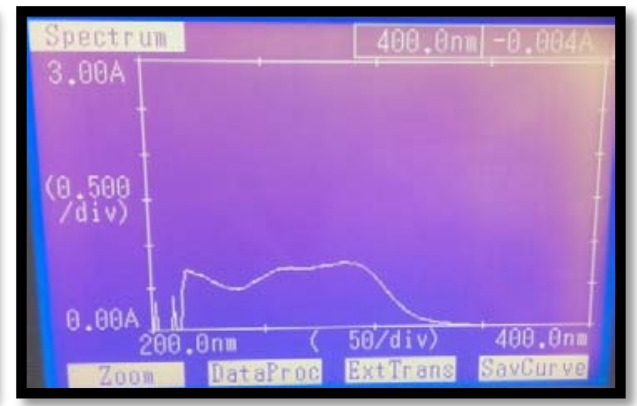

Formulation

Fig. 9: Thermal degradation of standard mixture and formulation 


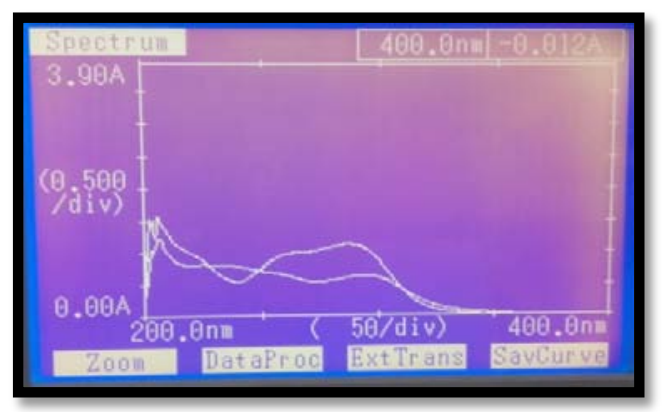

Std. mixture

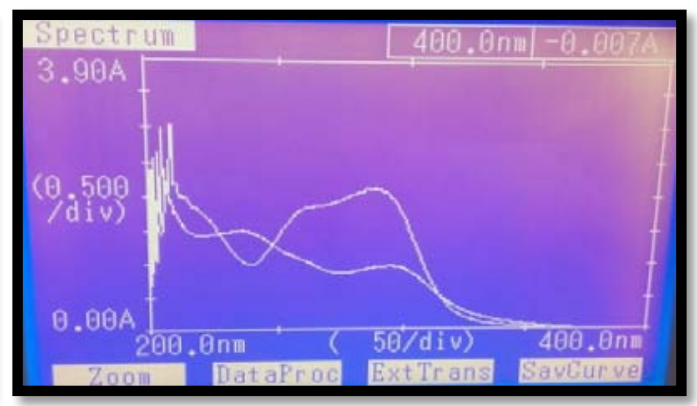

Formulation

Fig. 10: Photodegradation of standard mixture and formulation

The spectrum of all degradation study of standard mixture and formulation as shown in fig. 6-10. From that spectrum \% degradation was calculated and observed that more degradation was found in acid hydrolysis and photostability degradation.

\section{DISCUSSION}

For determination of ROS and FEN absorbance ratio method used. From the overlay spectra of both drugs, $249.5 \mathrm{~nm}$ selected as is absorptive point for estimation and another wavelength used was $\lambda$ max of fenofibrate. For this method, linearity was obtained in the range of $4-24 \mu \mathrm{g} / \mathrm{ml}$ for ROS and FEN, respectively. For ROS the correlation coefficient, intercept, the slope was found to be 0.999, 0.042, 0.047, respectively. For FEN the correlation coefficient, intercept, the slope was found to be $0.999,0.053,0.054$, respectively. The standard mixture and formulation studied by absorbance ratio method and amount of drug estimated, \% estimation was calculated by using the equation of absorbance ratio method. It was found within the prescribed limit. The validation of the proposed method was performed as per ICH guidelines with linearity, accuracy, precision, LOD, LOQ. In the accuracy study 100.83, 100.66, 100.55 percentage ROS and 100.41, 100.66, 100.55 percentage FEN recovered at 3 different recovery levels. The standard deviation and \% RSD value were found to be less than $2 \%$ shows the high precision and accuracy of the method. The robustness of the proposed method was calculated by changing the analyst and it was found within a limit. The detection limit and quantification limit were found to be 0.048 and $0.14 \mu \mathrm{g} / \mathrm{ml}$ for rosuvastatin and 0.069 and $0.210 \mu \mathrm{g} / \mathrm{ml}$ for fenofibrate, respectively. The forced degradation studies were performed by subjecting to the different stress conditions like acidic, alkaline, hydrolytic, oxidative, thermal, photostability. Major degradation was observed in acidic and photolytic conditions. In acidic condition, degradation of standard mixture and formulation was found to be $15.8 \%$ and $12.7 \%$. In photolytic conditions, degradation of standard mixture and formulation was found to be $38.14 \%$ and $51.50 \%$, respectively. This spectroscopic method provides versatile techniques for the analysis of drugs in the multi-component formulation. The method was found to be simple, precise, accurate and reproducible during an analysis of standard mixture and formulation containing both drugs.

\section{CONCLUSION}

The present work describes a simple, accurate, reproducible, stable, economical, and non-interfering spectrophotometric method for the simultaneous estimation of rosuvastatin calcium and fenofibrate in bulk as well as pharmaceutical formulation using the isoabsorptive point method.

\section{ACKNOWLEDGEMENT}

The authors wish to express their sincere thanks to adv. V. K. Secretory and Sau. H. K., member of ZP and president NMSM Shevgaon for their encouragement. The authors also express sincere thanks to Dr. Shashikant Pattan, principal AKCOBP Bodhegaon, for their help in making this research.

\section{FUNDING}

Nil

\section{AUTHORS CONTRIBUTIONS}

Apeksha Funde developed a method and performed validation. Jayshree Kokat performed stability testing. Both authors discussed the results and contributed to writing the manuscript.

\section{CONFLICT OF INTERESTS}

Declared none

\section{REFERENCES}

1. Bai MD. A comparative study of the efficacy of rosuvastatin and atorvastatin in combination with fenofibrate in dyslipidemia. Int J Sci Res 2016;51:211-4.

2. Sharma A, Pokra M, Bhargava AK. Comparative study of atorvastatin and rosuvastatin on serum lipid profile in cardiac patients with diabetes. Med Sci Clin Res 2018;6:288-97.

3. Rohit D, Shankar J. Comparative study of atorvastatin and rosuvastatin in combination with fenofibrate in mixed hyperlipidemia. Int J Pharmacol Clin Sci 2016;5:25-31.

4. Strain JD, Farver DK, Clem JR. A review of the rationale and clinical use of concomitant rosuvastatin and fenofibrate therapy. Clin Pharm Adv Appl 2010;2:95-104.

5. Anandakumar K, Vetsa S, Ramu C, Jayamaryapan M. Simultaneous estimation of rosuvastatin calcium and fenofibrate in bulk and tablet dosage form by UV-spectrophotometry and RP-HPLC. Stamford J Pharm Sci 2011;4:58-63.

6. Sevda RR, Ravetkar AS, Shirote PJ. UV-spectrophotometric estimation of rosuvastatin calcium and fenofibrate in bulk drug and dosage form using the simultaneous equation method. Int J Chem Res 2011;3:629-35. 
7. Potawale RS, Gabhe SY. Hptlc method for simultaneous determination of rosuvastatin and fenofibrate in bulk and pharmaceutical formulation. Int J Pharm Pharm Sci 2014;6:323-6.

8. Sharma S. Simultaneous estimation of rosuvastatin calcium and fenofibrate in bulk and tablet dosage form by UV-spectrophotometry and RPHPLC. J Pharm Res 2012;5:2311-4.

9. Borole TC, Dewani MG, Gandhi SP, Damale MC. Simultaneous estimation of rosuvastatin calcium and fenofibrate in their combined tablet dosage form by HPLC method. Asian J Res Chem 2011;4:1557-61.

10. Patel H, Rathode R, Dash RP. Simultaneous quantification of rosuvastatin and fenofibric acid by HPLC-UV in rat plasma and its application to a pharmacokinetic study. J Liq Chrom Tech 2014;37:1673-84.

11. Trivedi RK, Kalem RR, Mulangi R, Shrinivas RR. Simultaneous determination of rosuvastatin and fenofibric acid in human plasma by LC-MS/MS with electrospray ionization: assay development, validation, and application to a clinical study. J Pharm Biomed Anal 2005;15:3-4.

12. Kumar SA, Debnath M, Sankar DC. Development and validation of a sensitive RP-HPLC method for simultaneous estimation of rosuvastatin and fenofibrate in tablet dosage form by using PDA detector in gradient mode. Res J Pharm Tech 2016;9:549-54.

13. Vyas S, Raval K, Antala H. Development and validation of the derivative spectroscopic method for the simultaneous estimation of rosuvastatin calcium and fenofibrate in combined dosage form. Int J Res Pharm Nano Sci 2013;2:158-68.

14. Chaudhary J, Jain A, Saini V. Simultaneous estimation of multicomponent formulations by UV-visible spectroscopy: an overview. Int Res J Pharm 2011;2:81-3.

15. Singh S, Rai J, Choudhary N, Sharma S. Stability-indicating UV-vis spectrophotometric method for estimation of atorvastatin calcium and fenofibrate in tablet dosage form. Bulletin Pharm Res 2012;2:159-66.

16. Turabi ZM, Khatatbeh OA. Stability indicating RP-HPLC method development and validation for the determination of rosuvastatin in pharmaceutical dosage form. Int J Pharm Sci Drug Res 2014;6:154-9.

17. Ranjeet KV, Sai MD, Ajitha A, Uma MR. Development and validation of stability indicating RP-HPLC method for simultaneous estimation of atorvastatin and olmesaratn in the pharmaceutical dosage form. Int J Pharm Res Anal 2014;4:282-387.

18. Ranjit S. Zia R. Current trends in forced degradation study for pharmaceutical product development. J Pharm Edu Res 2012;3:54-63. 